\title{
DAPATKAH IT GOVERNANCE DENGAN COBIT 5 MENINGKATKAN KUALITAS LAYANAN INFORMASI AKADEMIK?
}

\author{
Komang Muda Sedana Yoga ${ }^{1}$, Novita ${ }^{2}$ \\ 1,2Universitas Trilogi, Jakarta, Indonesia \\ Email korespondensi: 2novita_1210@trilogi.ac.id
}

\begin{abstract}
ABSTRAK
Tujuan dari penelitian ini adalah untuk mengetahui pengaruh tata kelola teknologi informasi dengan menggunakan COBIT 5 sebagai kerangka kerja tata kelola teknologi informasi terhadap kualitas layanan informasi akademik pada Sistem Infromasi Akademik. Penelitian ini menggunakan analisis deskriptif kualitatif dan analisis partial least square. Data primer didapatkan melalui kuesioner yang disebarkan pada mahasiswa aktif Universitas Trilogi pada semester gasal tahun 2020-2021. Hasil dari penelitian ini menunjukkan COBIT 5 dengan domain EDM (evaluate, direct and monitor) dan domain MEA (monitor, evaluate and assess) berpengaruh positif terhadap peningkatan kualitas layanan pada sistem informasi akademik Universitas Trilogi. Sedangkan domain DSS (Delivery, Service and Support) tidak berpengaruh positif terhadap peningkatan kualitas layanan pada sistem informasi akademik Universitas Trilogi. Hasil penelitian ini menjadi masukan bagi Universitas Trilogi untuk terus meningkatkan tata kelola teknologi informasi pada sistem informasi akademik sebagai salah satu cara untuk meningkatan kualitas layanan yang diberikan agar visi dan misi universitas dapat tercapai.
\end{abstract}

Kata Kunci: COBIT 5; kualitas layanan; sistem informasi manajemen; tata kelola teknologi informasi

\section{ABSTRACT}

The purpose of this research is to see to what extent the implementation of information technology governance with COBIT 5 as a basic framework for assessing information technology and determine the effect of information technology governance on the academic information system. This data processing uses descriptive qualitative analysis and Partial Least Square analysis. The primary data was collected from the questionnaire that distributed to active student in odd semester 2020-2021 in Trilogi University. The result of this research is showing COBIT 5 with the domain EDM (Evaluate. Direct and Monitor) and the MEA (Monitor, Evaluate and Assess) domain have an effect on improving service quality at Trilogy University. While the DSS (Delivery, Service and Support) domain has no effect on improving service quality at Trilogi University. In consequence, Trilogi University is required to improve the governance of information technology in academic information system as way to enchance the service quality provided, so the vision and mission can be achieved.

Keywords: COBIT 5; information technology governance; management information system; service quality.

\section{KETERANGAN ARTIKEL}

Riwayat Artikel: diterima: 10 September 2021; direvisi: 11 November 2021; disetujui: 24 Desember 2021

Klasifikasi JEL: L86

Cara mensitasi: Yoga, K. M. S., \& Novita. (2021). Dapatkah IT Governance dengan COBIT 5 Meningkatkan Kualitas Layanan Informasi Akademik? JIMFE (Jurnal IImiah Manajemen Fakultas Ekonomi), 7(2), $231-244$. https://doi.org/ 10.34203/jimfe.v7i2.3905.

\section{(c) (i) (2)}

\section{PENDAHULUAN}

Sebelum perkembangan teknologi informasi menjadi sangat pesat seperti saat ini, media informasi yang digunakan oleh entitas termasuk perguruan tinggi masih berupa media cetak yang disebarkan melalui papan pengumuman maupun buletin di mana menuntut pengguna informasi untuk aktif 
Komang Muda Sedana Yoga: Dapatkah IT Governance ...

melihat pengumuman tersebut (Anggraeni \& Irviani, 2017). Kelemahan dari proses manual diantaranya proses yang bersifat parsial karena antara satu proses kerja dengan proses kerja lainnya tidak saling terhubung, sehingga seringkali output yang dihasilkan berbeda-beda dan dibutuhkan proses berikutnya untuk melakukan rekonsiliasi data dan informasi yang dapat digunakan sebagai dasar evaluasi maupun pengambilan keputusan. Sehingga seringkali dalam proses manual terjadi kesalahan yang terjadi berulang-ulang yang dapat berdampak pada efektivitas dan efisiensi entitas. Salah satu proses manual yang terjadi pada perguruan tinggi yaitu pada proses registrasi setiap semester dan proses yang terkait nilai mata kuliah yang ditempuh oleh mahasiswa. Permasalahn yang sering muncul pada saat proses manual untuk aktivitas registrasi mahasiswa setiap semester di antaranya ketidaksesuaian antara data yang ditulis oleh mahasiswa dalam form registrasi dengan yang daftar presensi kelas saat kuliah dimulai. Selanjutnya tidak jarang mahasiswa mengajukan protes karena nilai yang dipajang pada papan pengumuman nilai berbeda ketika mahasiswa mencetak transkrip nilai. Hal inilah yang memotivasi perguruan tinggi untuk mengembangkan sebuah sistem informasi akademik terintegrasi sehingga keandalan data dan informasi yang disajikan juga dapat diandalkan dalam pengambilan keputusan.

Sistem Informasi Akademik adalah sebuah sistem terintegrasi yang digunakan untuk memberikan layanan untuk mempermudah pengguna dalam kegiatan keadministrasian di perguruan tinggi (Sevima, 2020). Sistem informasi akademik juga bermanfaat untuk para dosen yaitu pada proses kemajuan perkuliahan, penginputan nilai mahasiswa, maupun dalam proses bimbingan tugas akhir. Dengan adanya sistem informasi akademik, mahasiswa dan dosen dapat langsung melakukan input sendiri apa saja yang harus diinput sesuai dengan ketentuan dan persyaratan. Sistem informasi akademik juga dapat berfungsi untuk mengontrol aktivitas baik dari sisi mahasiswa dalam melihat perkembangan perkuliahan maupun pembayaran, dosen untuk kemajuan perkuliahan, maupun perguruan tinggi dalam keandalan data akademik maupun keuangan. Untuk dapat memberikan keandalan data dan informasi yang disajikan agar relevan, dibutuhkan tata kelola teknologi informasi untuk mengontrol semua proses pada sistem.

Tata kelola merupakan kebijakan serta prosedur dengan kumpulan proses organisasi agar organisasi dapat memastikan kebijakan yang dibuat telah laksanakan sebagaimana mestinya untuk mencapai tujuan dari organisasi dengan melakukan optimalisasi terhadap pengendalian. Menurut penelitian Wahono (2015) diaktakan bahwa tata kelola khususnya teknologi informasi (TI) dikatakan penting karena digunakan dalam pengambilan keputusan dewan direksi. Menurut Maskur dkk. (2018) dikatakan bahwa tata kelola khususnya tata kelola TI (IT Governance) memiliki manfaat yaitu dalam menciptakan kesinambungan antara strategi bisnis dan strategi pengeloalaan, dapat mengeksploitasi kesempatan dan memaksimalkannya, melakukan manajemen risiko, penggunaan sumber daya yang memadai, dan performa yang dihasilkan dapat diukur secara reguler.

Tata kelola TI merupakan cabang dari sebuah tata kelola dalam perusahaan yang dasarnya difokuskan pada bagian sistem informasi dan teknologi informasi dengan menekankan manajemen kinerja dan manajemen risiko yang dihasilkan agar output yang dikeluarkan dapat diterima dengan jelas dan dapat digunakan untuk pengambilan keputusan pengguna informasi. Hal ini menjadi penting karena tata kelola teknologi informasi dapat mengintegrasikan sistem antar divisi atau bagian-bagian yang sifatnya operasional agar data antar divisi dapat diproses menjadi suatu informasi yang kemudian akan disampaikan kepada pengguna informasi (Zamzami dkk., 2015). Namun, dalam penerapannya, ada beberapa risiko yang kemungkinan terjadi dan untuk mencegah hal itu terjadi dibutuhkan sebuah kerangka kerja. Ada beberapa kerangka kerja yang dapat digunakan dalam mengimplementasikan tata kelola teknologi informasi, salah satunya adalah COBIT 5 untuk memberikan mengevaluasi pilihan strategis, memberikan arahan kepada teknologi informasi dan melakukan pemantauan hasil terhadap sistem informasi agar dapat memberikan kualitas layanan informasi yang diberikan.

COBIT 5 (Control Objectives for Information and Related Technology) merupakan salah satu 
kerangka kerja untuk mengaplikasikan tata kelola teknologi informasi yang berupa bukti dokumentasi dan arahan dalam membantu auditor dan manajemen untuk menjembatani pemisah (gap) antara resiko bisnis, kebutuhan kontrol dan permasalahan-permasalahan teknis (IT Governance Indonesia, 2019). COBIT 5 bermanfaat bagi manajemen untuk membantu menyeimbangkan antara resiko dan investasi pengendalian dalam sebuah lingkungan IT yang sering tidak dapat diprediksi. Penggunaan kerangka kerja COBIT 5 dapat dilakukan di semua organisasi atau instansi. Adapun penerapan COBIT 5 ini dapat dilakukan pada ekosistem sistem informasi yang digunakan oleh organisasi seperti yang dilakukan pada Pusat Data dan Teknologi Informasi Kementrian ESDM dalam melakukan kegiatan operasional internal dan kegiatan bisnis dengan pelanggan (Hakim, dkk. (2014). Contoh lain dalam penerapan tata kelola TI adalah layanan dan dukungan teknologi informasi pada perguruan tinggi swasta di kota Semarang dalam meningkatkan kematangan layanan TI untuk pengguna layanan dan kemudian dievaluasi untuk melihat apakah ada proses yang tidak efektif (Supardono, 2011). Ada juga penggunaan COBIT 4.1 yang diterapkan oleh PT Perkebunan Nusantara III Medan (Persero) (Sitohang, 2015).

Tata kelola TI pada sistem informasi, membutuhkan sebuah dukungan kebijakan yang jelas dan terarah pada sistem informasi oleh penentu kebijakan agar semua domain pada COBIT 5 dapat terintegrasi dengan baik (Maskur dkk., 2018). Walaupun user menerima layanan yang baik dengan adanya keberlanjutan tata kelola ini, organisasi harus terus melakukan peningkatan layanan dengan maksud menciptakan loyalitas user menjadi lebih tinggi lagi (Fikri dkk., 2016). Untuk mendukung keberlanjutan tata kelola TI dalam memberikan pelayanan yang baik, dibutuhkan SDM yang mampu mengoperasikan sistem informasi dengan baik agar user dapat merasakan pengalaman yang baik dalam menggunakan sistem. Untuk itu sebuah organisasi harus memberikan pelatihan kepada pegawai untuk semakin meningkatkan kinerja TI dalam memberikan layanan informasinya (Wicaksono dkk., 2020). Fungsi teknologi informasi dalam sebuah Perguruan Tinggi masih menjadi tulang punggung dalam menjalankan sebuah bisnis pada operasinya untuk pengambilan keputusan, sehingga dalam penerapan tata kelola teknologi informasi dapat mengingkatkan kualitas layanan informasi yang dihasilkan untuk manajemen dalam melakukan pemantauan dan mengevaluasi dan para pengguna layanan untuk menilai seberapa baik kualitas layanan yang diberikan (Maulidia dkk., 2013).

Kualitas layanan informasi yang baik dapat memberikan dampak yang positif bagi pengguna layanan salah satunya adalah hubungan yang baik. Hubungan yang baik ini dapat memungkinkan pemberi layanan untuk memahami apa yang menjadi harapan penerima layanan. Pemberi layanan memberikan layanan sebagai tindakan untuk memenuhi semua kebutuhan dan keinginan konsumen (Kotler \& Keller, 2016). Pelayanan yang diberikan dapat menghasilkan sebuah kepuasan yang berdampak pada kualitas layanan berkelanjutan agar menjadi lebih baik. Layanan yang baik adalah bagaimana layanan diberikan dengan tepat dan memenuhi harapan penerima layanan dengan bersikap baik, ramah, dapat membantu dan mengatasi permasalahan yang dialami dengan profesional. Layanan informasi yang diberikan dapat membantu konsumen melihat lebih luas tentang produsen atas produk yang dibeli konsumen ataupun produk lain pada produsen yang sama (Utari dkk., 2018). Hal ini tentu dapat memberikan kepuasan dan loyalitas yang baik apabila kualitas layanan informasi juga diberikan dengan baik. Dengan melakukan tata kelola TI pada sistem informasi yang baik, maka akan memberikan kualitas layanan yang baik pula dengan disertai penggunaan kerangka kerja yang digunakan harus mencangkup semua bagian pada organisasi (Pardiansyah, 2015).

Kebaruan penelitian ini yaitu menggunakan COBIT 5 sebagai dasar kerangka untuk menilai tata kelola teknologi informasi akademik pada perguruan tinggi. Hasil dari penelitian ini dapat menjadi masukan bagi perguruan tinggi bahwa mengimplementasikan COBIT 5 sebagai kerangka kerja tata kelola teknologi informasi dapat memberikan perbaikan yang berkesinambungan dan berkelanjutan 
Komang Muda Sedana Yoga: Dapatkah IT Governance ...

dapat yang signifikan terhadap sistem informasi akademik yang diimplementasikan. Penerapan COBIT 5 sebagai kerangka kerja tata kelola informasi yang dilakukan bertahap juga dapat memberikan kualitas layanan baik pada sistem informasi akademik kampus. Bagi pengelola kampus khususnya pengelola teknologi informasi, penelitian ini juga dapat memiliki dampak terhadap pengendalian risiko pada sistem informasi akademik kampus.

Universitas Trilogi mengalami perubahan sistematika terhadap sistem informasi akademik yang sebelumnya bersifat manual hingga menjadi sistem informasi akademik berbasis intranet yang sangat kompleks pada tahun 2004. Saat itu Sistem Informasi Akademik Trilogi (SIAT) hanya mengintegrasikan antara mahasiswa, administrasi akademik, dosen dan kaprodi untuk proses perkuliahan dan kemudian pada tahun 2018 Universitas Trilogi melakukan pergantian sistem informasi akademik yang menjadikan Sistem Informasi Akademik Trilogi lebih kompleks dan dalam prosesnya memudahkan para pengguna untuk mengakses kebutuhan yang terkait dengan perkuliahan mulai dari mengubah data mahasiswa, pengisian Kartu Rencana Studi (KRS), pendaftaran proposal skripsi, hingga keuangan yang bisa dilakukan sendiri oleh mahasiswanya. Manfaat penggunaan Sistem Informasi Akademik yang digunakan oleh Universitas Trilogi saat ini sangat membantu dan mempermudah para sivitas akademika dalam mengatur menu yang ada salah satunya untuk melakukan audit tata kelola pada sistem untuk meningkatkan kualitas layanan informasi. Oleh karena itu, penelitian ini bertujuan untuk mengetahui penerapan tata kelola teknologi informasi dengan COBIT 5 dalam meningkatkan kualitas layanan sistem informasi akademik di Universitas Trilogi.

\section{KAJIAN LITERATUR DAN PENGEMBANGAN HIPOTESIS}

\section{Tata Kelola Teknologi Informasi}

Teknologi informasi saat ini telah digunakan hampir di semua organisasi baik pemerintah, industri, swasta, dunia pendidikan bahkan hingga usaha kecil. Hal ini diyakinkan bahwa TI dapat meningkatkan efisiensi dan efektifitas proses-proses dal bisnis yang dilakukan organisasi demi mencapai tujuannya. Hal ini tentu dapat berimbas bagi perguruan tinggi yang dalam proses bisnisnya memerlukan dukungan TI untuk meningkatkan efektivitas dan efisiensi proses bisnisnya. Namun, dalam implementasinya, kebanyakan perguruan tinggi jarang mengevaluasi sejauh mana layanan berbasis $\mathrm{TI}$ dapat dikelola dan dikontrol untuk mendukung proses-proses bisnis perguruan tinggi dalam memberikan layanan terbaiknya (Lutfianto, 2017). Dengan adanya sebuah tata kelola TI, civitas perguruan tinggi dapat dengan mudah menjalankan bisnisnya mulai dari penerimaan mahasiswa, integrasi keuangan. Oleh karena itu, untuk dapat memberikan kualitas layanan yang mumpuni untuk para konsumennya, dibutuhkan sebuah tata kelola teknologi informasi agar organisasi mendapatkan nilai yang berbeda dengan organisasi lain di mata konsumennya. Hal ini didukung penelitian dari Pardiansyah (2015) yang menjelaskan bahwa tingkat kematangan tata kelola TI dapat berdampak kepada semua pengguna dan respons pengguna menjadi tolok ukur seberapa baiknya kualitas layanan yang diberikan oleh pengelola. Salah satu kerangka kerja yang dapat dijadikan sebagai panduan dalam melakukan tata kelola TI adalah COBIT 5.

\section{COBIT 5 Dalam Upaya Meningkatkan Kualitas Layanan}

Konsep COBIT 5 merupakan sebuah konsep tata kelola teknologi informasi yang mempertemukan apa yang dibutuhkan oleh manajemen dengan berbagai kebutuhan kontrol untuk mengatasi masalahmasalah teknis TI dan risiko-risiko bisnis organisasi dalam mengelola sumber daya TI untuk mencapai tujuan organisasi. COBIT 5 juga dapat diartikan sebagai proses integrasi dalam tata kelola TI yang menyediakan prinsip, praktik alat analisa yang dapat meningkatkan kepercayaan dan nilai-nilai sistem informasi bagi organisasi yang dibangun berdasarkan standar-standar ISO (Vitrin dkk., 2019). COBIT juga dapat diartikan sebagai kerangka kerja TI untuk penentuan kendali TI yang didasarkan pada proses 
TI dan sumber daya untuk menghasilkan informasi dalam mendukung tujuan bisnis organisasi (Utomo \& Novita, 2011). Di dalam COBIT 5 ada beberapa domain yang dapat membantu organisasi dalam melakukan proses tata kelola TI pada sistem. Domain tersebut adalah EDM (Evaluate, Direct and Monitor), DSS (Delivery, Service and Support), dan MEA (Monitor, Evaluate and Assess).

EDM (Evaluate, Direct and Monitor) merupakan proses pengelolaan yang erat kaitannya dengan pemangku kepentingan dengan melakukan pengiriman tujuan kepada konsumen, meminimalisir risiko dan mengoptimalkan sumber daya yang ada pada perusahaan dengan tujuan untuk melakukan evaluasi dan memberikan arahan kepada manajemen TI untuk melakukan pemantauan terhadap hasil evaluasi. EDM memiliki beberapa proses, yaitu EDM01 Ensure Governance Framework Setting and Maintenance, EDM02 Ensure Benefits Delivery, EDM03 Ensure Risk Optimisation, dan EDM04 Ensure Resource Optimisation. Penelitian Wijayanto dkk. (2018) untuk mencapai hal yang dapat mendukung pelayanan dan penyampaian informasi harus ada pengembangan bertahap sesuai kapabilitas pada prosesnya. Penelitian Vitrin dkk. (2019) bahwa dengan adanya menu yang dapat mengelola permintaan atas insiden layanan, mengelola masalah dengan cepat dan mengelola sistem yang berkelanjutan agar sistem berjalan sesuai dengan harapan konsumen. Penelitian Hakim dkk. (2014) bahwa dengan melakukan optimalisasi pada sistem pelaporan sesuai dengan perencanaan dan berpedoman pada kebijakan dapat memberikan hasil yang sesuai dengan yang diberikan kepada pemangku kepentingan. Penelitian Utomo \& Novita (2011) bahwa dengan adanya batasan proses yang harus beroperasi dengan laporan Monitoring dapat memberikan pelaporan yang sistematis dan tepat waktu kepada konsumen.

DSS (Delivery, Service and Support) merupakan domain yang menerima solusi dari manajemen untuk perbaikan pada sistem untuk akhirnya akan digunakan oleh konsumen (end user). DSS berkaitan erat dengan pengadaan layanan yang dibutuhkan meliputi pelayanan terhadap keluhan, pengelolaan keamanan data konsumen dan kelangsungan hubungan antara pemberi layanan dan konsumen, manajemen data pada sistem pemberi layanan dan fasilitas operasional yang ada dalam memberikan layanan. DSS memiliki enam proses, yaitu DSS01 Manage Operations, DSSO2 Manage Service Requests and Incidents, DSS03 Manage Problems, DSS04 Manage Continuity, DSS05 Manage Security Services, DSS06 Manage Business Process. Penelitian Wijayanto dkk. (2018) untuk mencapai hal yang dapat mendukung pelayanan dan penyampaian informasi harus ada pengembangan bertahap sesuai kapabilitas pada prosesnya. Penelitian Vitrin dkk. (2019) bahwa dengan adanya menu yang dapat mengelola permintaan atas insiden layanan, mengelola masalah dengan cepat dan mengelola sistem yang berkelanjutan agar sistem berjalan sesuai dengan harapan konsumen.

Penelitian Vitrin dkk. (2019) bahwa dengan melakukan pemantauan, evaluasi agar sesuai dengan data yang diberikan baik dengan melakukan pengendalian internal dan peraturan yang berlaku. Penelitian Hakim dkk. (2014) bahwa dengan melakukan optimalisasi pada sistem pelaporan sesuai dengan perencanaan dan berpedoman pada kebijakan dapat memberikan hasil yang sesuai dengan yang diberikan kepada pemangku kepentingan. Penelitian Utomo \& Novita (2011) bahwa dengan adanya batasan, proses yang berjalan harus beroperasi sesuai dengan laporan Monitoring sehingga dapat memberikan pelaporan yang sistematis dan tepat waktu kepada konsumen.

MEA merupakan domain yang erat kaitannya dengan proses pemantauan pada hasil yang sudah dievaluasi, baik berjalannya peraturan yang ada dijalankan oleh karyawan maupun pada proses tata kelola TI. MEA memiliki tiga proses, yaitu MEA01 Monitor, Evaluate and Assess Performance and Conformance, MEA02 Monitor, Evaluate and Assess System of Internal Control, dan MEA03 Monitor, Evaluate and Assess Compliance with External Requirements. Penelitian Wijayanto dkk. (2018) untuk mencapai hal yang dapat mendukung pelayanan dan penyampaian informasi harus ada pengembangan bertahap sesuai kapabilitas pada prosesnya. Penelitian Vitrin dkk. (2019) bahwa dengan adanya menu 
Komang Muda Sedana Yoga: Dapatkah IT Governance ...

yang dapat mengelola permintaan atas insiden layanan, mengelola masalah dengan cepat dan mengelola sistem yang berkelanjutan agar sistem berjalan sesuai dengan harapan konsumen.

Penelitian Vitrin dkk. (2019) bahwa dengan melakukan pemantauan dan evaluasi agar sesuai dengan data yang diberikan, diperlukan sebuah pengendalian yang baik pada internal perusahaan dan ketaatan terhadap peraturan yang berlaku. Penelitian Hakim dkk. (2014) bahwa dengan melakukan optimalisasi pada sistem pelaporan sesuai dengan perencanaan dan berpedoman pada kebijakan dapat memberikan hasil yang sesuai dengan yang diberikan kepada pemangku kepentingan. Penelitian Utomo \& Novita (2011) bahwa dengan adanya batasan proses yang harus beroperasi dengan laporan Monitoring dapat memberikan pelaporan yang sistematis dan tepat waktu kepada konsumen.

$\mathrm{H}_{1}$ : pengaruh positif dari EDM (evaluate, direct and monitor) pada sistem informasi akademik terhadap kualitas layanan informasi akademik.

$\mathrm{H}_{2}$ : pengaruh positif dari DSS (delivery, services and support) pada sistem informasi akademik terhadap kulitas layanan informasi akademik.

$\mathrm{H}_{3}$ : pengaruh positif dari MEA (monitor, evaluate and assess) pada sistem informasi akademik terhadap kulitas layanan informasi akademik.

\section{METODE PENELITIAN}

Penelitian ini dilakukan pada mahasiswa yang sedang menempuh pendidikan dan orang yang memiliki otoritas pada bagian Sistem Informasi Akademik Trilogi (SIAT) di lembaga pendidikan tinggi yaitu Universitas Trilogi. Penelitian ini dilakukan pada tahun 2020. Populasi dan sampel dalam penelitian ini dilakukan pada mahasiswa dan karyawan Universitas Trilogi Universitas Trilogi Jakarta, Jl. TMP Kalibata No. 4, Duren Tiga, Kec. Pancoran, Jakarta, Daerah Khusus Ibukota Jakarta 12760. Populasi yang digunakan dalam penelitian ini adalah mahasiswa aktif Universitas Trilogi angkatan 2016-2020 yang masih memiliki SKS di semester gasal 2020-2021 dan S1 Reguler dan Ekstensi (Karyawan) seluruh fakultas yang sedang menempuh pendidikan di Universitas Trilogi. Adapun dasar pemilihan angkatan 2016-2020 dikarenakan mayoritas mahasiswa aktif pada periode penelitian adalah angkatan 20162020.

Metode pengambilan sampel yang digunakan dalam penelitian ini adalah probability sampling dimana teknik sampel ini memberikan peluang yang sama untuk setiap anggota populasi setiap anggota populasi terpilih untuk dijadikan sampel penelitian (Sekaran \& Bougie, 2013). Untuk menentukan sampel yang terpilih maka selanjutnya menggunakan teknik simple random sampling dimana setiap unit sampling sebagai unsur populasi yang terpencil memperoleh peluang yang sama untuk menjadi sampel penelitian yang mewakili populasi penelitian (Sekaran \& Bougie, 2013). Teknik ini dipilih karena populasi penelitian yang homogen yaitu mahasiswa aktif yang dalam proses perkuliahan menggunakan sistem informasi akademik. Dengan menggunakan rumus sampel dari populasi terbatas sebagai berikut maka diperoleh minimal sampel adalah 331 responden. Selanjutnya dilakukan penyebaran kuisioner melalui gform maka diperoleh sebanyak 336 tanggapan responden yang akan diolah lebih lanjut.

Data ini didapat melalui hasil kuesioner dengan fakta-fakta yang ada dan hubungannya dengan penerapan tata kelola teknologi informasi di Universitas Trilogi. Keakuratan data yang diperoleh dapat dipertanggungjawabkan dan dapat memberikan informasi yang berguna dalam penelitian ini. Data diperoleh dengan cara menyebar kuesioner dengan rating scale 1-6 dimana skala 1 menunjukkan Sangat tidak setuju sekali dan skala 6 menunjukkan sangat setuju sekali. Semakin tinggi angka yang dihasilkan dari jawaban responden maka dapat diartikan sebagai respons baik atas pernyataan yang diberikan (Sugiyono, 2011). Penelitian ini menggunakan variabel independen internal COBIT 5 dengan domain tata kelola dan domain manajemen (EDM, DSS, dan MEA) dan variabel dependen kualitas layanan.

Pengujian data menggunakan dua analisis yang digunakan adalah analisis deskriptif dan analisis verifikatif SEM (structural equation modeling) dengan alat PLS (partial least square). Analisis deskriptif 
digunakan untuk menganalisis tentang penerapan tata kelola teknologi informasi berbasis COBIT 5 untuk meningkatkan kualitas layanan. Analisis verifikatif dalam SEM memiliki dua sub model yaitu dengan menggunakan pengukuran outer model dan evaluasi model struktural (Inner model), kemudian masuk pada tahap pengujian hipotesis (Ghozali \& Latan, 2015). Pertama dengan pengukuran Outer model atau sering disebut outer relation atau measurement model yaitu menunjukkan bagaimana variabel yang diamati dan diukur merepresentasikan variabel laten untuk diukur.

Pengujian verifikatif bertujuan untuk menguji kendalan data sebelum pengujian hipotesis. Dengan uji validitas menggunakan beberapa metode pengujjian yaitu dengan nilai Convergent validity minimal 0,50, Discriminant validity minimal 0,70, dan Average Variance (AVE) minimal 0,50 maka di antara variabel yang ada memiliki nilai validitas yang baik pada setiap konstruknya. Lalu dengan Evaluasi reliabilitas menggunakan beberapa metode pengujian yaitu Cronbach's alpha, Composite reliability. Apabila salah satu evaluasi reabilitas ada yang memiliki angka dibawah 0,50 namun mendekati $(0,450$ 0,499 ) maka data tersebut masih realibel untuk dilakukan pengujian lanjutan hipotesis (Ghozali \& Latan, 2015). Selanjutnya pengukuran evaluasi model struktural digunakan untuk menunjukkan kekuatan estimasi yang terjadi antara variabel laten dan konstruk. Analisis ini dilakukan dengan beberapa tahapan, yaitu Path Coefficient dengan nilai di atas $(0,000)$ berarti variabel dependen memiliki pengaruh terhadap variabel independen, $R$ Square $\left(R^{2}\right)$ dengan nilai konstruk di atas $(0,330)$ dapat dikatakan mempunyai hubungan konstruk yang moderat dan nilai kapabilitas predikisi atau Predictive relevance dengan nilai 0,02 dapat dikatakan lemah, lalu nilai 0,15 dapat dikatakan moderat dan 0,35 dapat dikatakan kuat. Selanjutnya pengujian hipotesis, dengan tingkat keyakinan $95 \%$ dan alpha sebesar $5 \%$ sehingga t-tabel sebesar 1,96.

\section{HASIL DAN PEMBAHASAN}

\section{Analisis Deskriptif Variabel COBIT 5}

COBIT 5 pada sistem informasi akademik kampus sudah baik karena sudah berada pada angka di atas tiga hal ini mendukung penelitian (Hakim dkk., 2014) yang dijelaskan pada Gambar 1 bahwa mahasiswa Universitas Trilogi merasa bahwa penerapan dengan sub variabel EDM memiliki nilai 4,64, DSS memiliki nilai 3,96 dan MEA memiliki nilai 4,11. Proses ini memiliki dua indikator tambahan untuk menentukan pengukuran untuk mencapai proses hasil, yaitu proses defiinisi dan proses penyebaran.

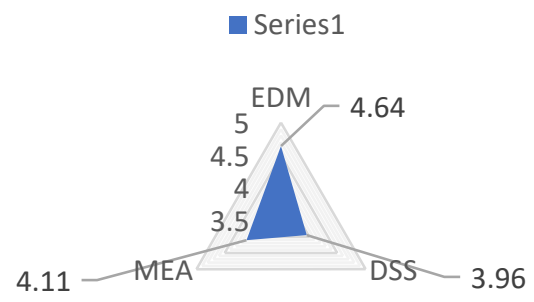

\section{Gambar 1. Tanggapan Responden Terhadap Variabel COBIT 5}

Untuk menentukan sejauh mana standar proses pengelolaan sistem yang dilaksanakan, Universitas Trilogi harus terlebih dahulu memiliki standar proses dalam sistemnya. Tentu saja hal ini harus dimulai dari interaksi dengan proses lainnya, kompetensi sumber daya dalam pengukuran proses, pengembangan proses, pelaksanaan monitor process yang sedang berjalan dan kemauan untuk terus meningkatkan penerapan COBIT 5 terutama untuk setiap domain atau konsep yang ada dalam COBIT 5 pada tata kelola TI. Mahasiswa yang memberikan respons baik didasarkan pada hal yang 
dialami sebenarnya dalam menggunakan sistem informasi akademik yaitu mulai dari adanya user guide, lengkapnya menu-menu yang ada pada sistem informasi akademik, tidak adanya kendala saat mahasiswa melakukan unggah dan unduh file, update informasi yang berkala pada sistem, hingga penyampaian informasi yang sesuai dengan data yang dimiliki mahasiswa.

\section{Analisis Deskriptif Variabel Kualitas Layanan}

Kualitas layanan yang diberikan oleh Universitas Trilogi sudah dapat dirasakan dengan baik karena variabel kualitas layanan yang terdapat lima sub variabel yaitu tangible, reability, responsiveness, assurance dan empathy memiliki rata-rata nilai terhadap variabel kualitas layanan beada di atas 3,000 dengan masing-masing nilai sub variabel tangible $(4,510)$, reability $(4,270)$, responsiveness $(4,610)$, assurance $(4,440)$ dan empathy $(4,270)$ dan hasil ini mendukung penelitian (Zamzami \& Novita, 2020). Universitas sudah memberikan kenyamanan dalam sistem informasi akademik kampus terutama pada ketersediaan menu dan fungsi sistem yang ada pada sistem informasi akademik kampus sebagai salah satu unsur kualitas layanan informasi akademik.

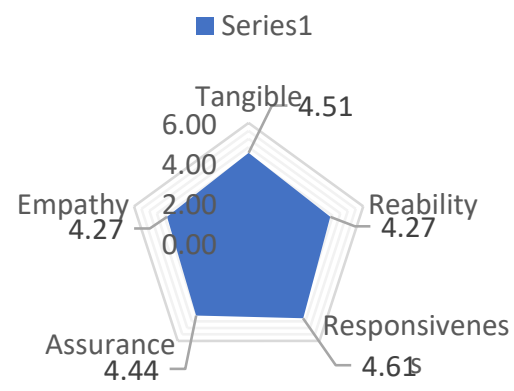

\section{Gambar 2 Tanggapan Responden Terhadap Variabel Kualitas Layanan}

Selanjutnya unsur dari kualitas layanan seperti tangible terlihat dari universitas dalam memberikan kepuasan yang terbaik bagi mahasiswa dengan memberikan penunjang yang lengkap pada sistem informasi akademik, sedangkan reability dicerminkan dari pemberian layanan kepada mahasiswa secara efektifitas, dan efisiensi seperti pemberian layanan yang konsisten dan berkelanjutan, pemberian informasi dan arahan yang akurat dan sistem dapat diandalkan. Indikator responsiveness dapat diartikan bahwa bagaimana universitas memberikan respons atau tanggapan yang diberikan oleh universitas apabila mahasiswa memiliki kendala pada setiap kegiatan dalam perkuliahannya seperti pelayanan yang cepat. Selanjutnya, assurance yang terapkan oleh Universitas Trilogi dalam memberikan jaminan atau kepastian atau rasa kepercayaan yang akan diperoleh oleh mahasiswa atas setiap layanan informasi akademik seperti terjaminnya data yang diinput ataupun yang di-unduh, dan pengalaman dalam melayani masalah dan empati merupakan sikap dari para staf biro administrasi akademik dalam memberikan layanan yang baik dengan memberikan perhatian dan pengertian yang tulus dan ramah kepada mahasiswa tanpa mengharapkan timbal balik balasan.

\section{Analisis Verifikatif}

Nilai validitas konstruk pada awal pengujian data, ada beberapa data yang belum memenuhi kriteria dari nilai validitas konstruk di bawah 0,7 . Namun, apabila nilai konstruk masih di bawah 0,7 , beberapa data harus dieliminasi untuk dapat menunjukkan (AVE) minimal di atas 0,5. Setelah dilakukan modifikasi untuk setiap model struktural untuk mendapatkan nilai outer loading yang baik sesuai kriteria maka dari total 58 indikator, empat belas indikator dieliminasi dan sisanya diolah dan dianalisis, di mana hasil nilai (AVE) untuk EDM $(0,525)$, DSS $(0,667)$, MEA $(0,637)$, dan Kualitas Layanan $(0,505)$. 
Tabel 1. Average Variance Extracted

\begin{tabular}{lc}
\hline & Average Variance Extracted (AVE) \\
\hline EDM & 0,525 \\
DSS & 0,667 \\
MEA & 0,637 \\
Kualitas Layanan & 0,505 \\
\hline
\end{tabular}

Berdasarkan Tabel 1 dapat dilihat bahwa semua konstruk memiliki AVE di atas 0,50 artinya jika dilihat dari nilai AVE maka diantara variabel yang ada memiliki nilai validitas yang baik pada setiap konstruknya.

Tabel 2. Hasil Uji Reliabilitas

\begin{tabular}{lcc}
\hline & Cronbach's Alpha & Composite reliability \\
\hline EDM & 0,923 & 0,934 \\
DSS & 0,915 & 0,923 \\
MEA & 0,484 & 0,772 \\
Kualitas Layanan & 0,955 & 0,959 \\
\hline
\end{tabular}

Tabel 2 memberikan informasi tentang nilai composite reliability setiap variabel. EDM memiliki keandalan data di atas 0,70 , sehingga variabel yang ada memenuhi kriteria composite reliability dan hasilnya memiliki keandalan data yang baik. Dengan hasil tersebut maka penelitian ini dapat dipercaya dengan menggunakan data yang tepat dikarenakan memiliki tingkat konsistensi nilai yang cukup dan apabila dilakukan pengujian kembali diharapkan dapat menghasilkan nilai yang sama.

Dari data di atas pada variabel MEA yang memiliki nilai Cronbach's alpha sebesar 0,484 karena ada beberapa indikator yang dieliminasi karena untuk memenuhi kebutuhan AVE sehingga dapat menimbulkan nilai di bawah 0,70 . Meskipun hal tersebut tidak berada di atas 0,70 , sudah cukup realibel. Penelitian ini tetap masih dapat dipercaya dengan menggunakan data yang tepat karena memiliki tingkat konsistensi nilai yang cukup.

Tabel 3. Nilai Path Coefficient

\begin{tabular}{lc}
\hline & Kualitas Layanan \\
\hline EDM & 0,627 \\
DSS & 0,085 \\
MEA & 0,285 \\
\hline
\end{tabular}

Pengujian dilakukan terhadap variabel Kualitas Layanan yang dapat dilihat pada Tabel 3 Nilai Path Coefficient COBIT 5 dan kualitas layanan menunjukkan bahwa konstruk EDM memberikan pengaruh positif sebesar 0,627 , DSS memberikan pengaruh positif sebesar 0,085, dan MEA juga memberikan pengaruh positif terhadap kualitas layanan sebesar 0,285. Yang dapat disimpulkan dari pengujian ini adalah semua konstruk memiliki pengaruh yang positif terhadap kualitas layanan.

Tabel 4. Nilai $R$ Square

\begin{tabular}{ccc}
\hline & $\boldsymbol{R}$ Square & $\boldsymbol{R}$ Square Adjusted \\
\hline Kualitas Layanan & 0,634 & 0,630 \\
\hline
\end{tabular}

Pada Tabel 4 menunjukkan $R$ Square (R2) untuk kualitas layanan didapat pada angka 0,634 sehingga arti bahwa sebesar 63,4\% EDM, DSS dan MEA mempengaruhi variabel kualitas layanan dan 
sisanya sebesar $36,6 \%$ dipengaruhi oleh variabel lain yang tidak digunakan dalam pengolahan data. Hasil yang didapat tersebut diperkuat oleh adanya hasil Adjusted $R$ Square yang nilainya tidak jauh berbeda dengan $R$ Square yaitu ada pada angka 0,630 atau $63 \%$ yang menyatakan hubungan yang lebih menyeluruh antara indikator di dalamnya.

Tabel 5. Nilai Blindfolding

\begin{tabular}{lc}
\hline \multicolumn{1}{c}{ Variabel } & Blindfolding Calculation \\
\hline EDM & 0,000 \\
DSS & 0,000 \\
MEA & 0,000 \\
Kualitas Layanan & 0,307 \\
\hline
\end{tabular}

Pengujian dilakukan pada variabel kualitas layanan untuk mengetahui kapabilitas prediksi dengan prosedur Blindfolding dengan kriteria predictive relevance dengan nilai 0,02 dapat dikatakan lemah, lalu nilai 0,15 dapat dikatakan moderat dan 0,35 dapat dikatakan kuat. Tabel 5 dapat disimpulkan jika hasil predictive relevance pada kualitas layanan sebesar 0,307 yang berarti variabel EDM, DSS dan MEA memiliki predictive relevance moderat pada variabel kualitas layanan.

Tabel 6. Hasil Bootstrapping

\begin{tabular}{lccccc}
\hline & $\begin{array}{c}\text { Original } \\
\text { Sample } \\
(\mathbf{O})\end{array}$ & $\begin{array}{c}\text { Sample } \\
\text { Mean } \\
(\mathbf{M})\end{array}$ & $\begin{array}{c}\text { Standard } \\
\text { Deviation } \\
\text { (STDEV) }\end{array}$ & $\begin{array}{c}\text { T Statistics } \\
(\mid \mathbf{O} / \text { STDEV|) }\end{array}$ & $\begin{array}{c}\text { P } \\
\text { Values }\end{array}$ \\
\hline EDM $\rightarrow$ Kualitas Layanan & 0,627 & 0,628 & 0,062 & 10,069 & 0,000 \\
DSS $\rightarrow$ Kualitas Layanan & 0,085 & 0,072 & 0,078 & 1,089 & 0,276 \\
MEA $\rightarrow$ Kualitas Layanan & 0,285 & 0,290 & 0,070 & 4,098 & 0,000 \\
\hline
\end{tabular}

EDM (Evaluate, Direct and Monitor) dalam meningkatkan Kualitas Layanan

Tabel 6 menunjukkan hasil dari pengujian hipotesis 1 yang memiliki hubungan antara EDM dengan Kualitas Layanan. Berdasarkan hasil pengujian dapat dijelaskan bahwa nilai original sampel memberikan informasi besar koefisien parameter sebesar 0,627 yang berarti terdapat pengaruh yang positif dan signifikan antara EDM di Universitas dalam meningkatkan kualitas layanan dengan nilai tstatistik sebesar 10,069 dan nilai P-Value sebesar 0,000. Hal ini menunjukkan bahwa hipotesis 1 diterima dan berdasarkan hasil tersebut terdapat pengaruh EDM dalam meningkatkan kualitas layanan. Hal ini sesuai dengan studi literatur dari (Ghozali \& Latan, 2015) yang dapat diartikan bahwa terdapat pengaruh yang positif penerapan COBIT 5 dengan indikator EDM (Evaluate, Direct and Monitor) di Universitas Trilogi dalam meningkatkan kualitas layanan informasi.

Dari penjabaran yang dijelaskan pada Tabel 6, mendukung penelitian yang dilakukan Suryono dkk. (2018) dan Utari dkk. (2018) bahwa dengan menyediakan peralatan yang lengkap pada sistem informasi dapat mengatasi dan mengurangi risiko yang muncul pada sistem informasi. Hasil penelitian ini juga mendukung penelitian yang dilakukan Fikri dkk. (2016) bahwa EDM (Evaluate, Direct and Monitor) dapat dijalankan pada sistem informasi akademik kampus karena adanya upaya yang dilakukan oleh universitas dalam melakukan optimisasi risiko, mengirimkan tujuan dan nilai berdasarkan dibuatnya sistem dan kemudian untuk mengevaluasi pilihan strategis yang akan diambil baik bagi mahasiswa yang menggunakan sistem ataupun universitas dalam melakukan evaluasi atas pemberian layanan. Dengan rutin melakukan optimisasi risiko terhadap permasalahan-permasalahan yang terjadi dapat membuat sistem semakin optimal sehingga kualitas layanan pun akan meningkat 
sesuai dengan harapan. Hal ini juga mendukung penelitian Wicaksono dkk. (2020) apabila EDM sudah sampai pada level 3 maka proses yang telah dideskripsikan telah dijalankan menggunakan proses yang lebih didefinisikan sehingga dapat mencapai tujuan prosesnya meskipun manajemen risiko telah berjalan tetapi masih terdapat beberapa kekurangan dalam menjalankan manajemen risiko.

Responden menunjukkan jika dalam proses penerapan EDM yang diterapkan pada sistem informasi akademik berpengaruh positif baik dari sisi tangible, reliability, responsiveness, assurane hingga empathy terhadap kepuasan yang diberikan kepada mahasiswa dengan kelengkapan menumenu pada sistem informasi akademik yang dapat diakses oleh mahasiswa untuk melihat bagaimana risiko dioptimisasi sudah diberikan dan sistem informasi yang berjalan dengan baik. Artinya, mahasiswa menerima dan merasakan kualitas layanan yang diberikan sudah sesuai dengan harapan yang diinginkan mahasiswa.

\section{DSS (Delivery, Service and Support) dalam meningkatkan Kualitas Layanan}

Tabel 6 menunjukkan hasil dari pengujian hipotesis 2 yang memiliki hubungan antara DSS dengan kualitas layanan. Berdasarkan hasil pengujian dapat dijelaskan bahwa nilai original sampel memberikan informasi besar koefisien parameter sebesar 0,085 yang berarti tidak terdapat pengaruh yang positif antara DSS di universitas dalam meningkatkan kualitas layanan dengan nilai t-statistik sebesar 1,089 dan nilai $P$-Value sebesar 0,276 dan hal ini menjelaskan bahwa DSS tidak diterapkan dengan baik oleh Universitas Trilogi pada sistem informasi akademik. Sehingga hipotesis 2 ditolak dan berdasarkan hasil tersebut tidak terdapat pengaruh antara DSS dalam meningkatkan kualitas layanan.

Dari penjabaran yang dijelaskan pada Tabel 6, dapat disimpulkan bahwa DSS (Delivery, Service and Support) tidak dijalankan dengan baik pada sistem informasi akademik kampus meskipun sudah ada upaya yang diberikan dengan mengadakan layanan diluar sistem informasi akademik kampus melalui Whatsapp. Namun, ini menjadi kelemahan bagi universitas karena informasi ini tidak semua mahasiswa mengetahuinya ditambah lagi dengan tidak adanya menu bantuan pada sistem informasi akademik menjadikan penyampaian layanan yang diberikan tidak dapat memberikan rasa puas kepada mahasiswa. Hal ini menunjukkan bahwa manajemen yang berkelanjutan tidak dilakukan pada sistem informasi akademik kampus sehingga harus ada perbaikan pada sistem informasi akademik kampus untuk menambahkan fitur yang dapat menerima dan menginformasikan layanan yang berhubungan dengan masalah yang dialami mahasiswa. Hal ini juga sesuai dengan penelitian Wijayanto dkk. (2018) untuk mencapai hal yang dapat mendukung pelayanan dan penyampaian informasi harus ada pengembangan bertahap sesuai kapabilitas pada prosesnya. Namun hal ini berkebalikan dengan penelitian Vitrin dkk. (2019) bahwa dengan adanya menu yang dapat mengelola permintaan atas insiden layanan, mengelola masalah dengan cepat dan melakukan proses yang berkelanjutan agar sistem berjalan sesuai dengan harapan konsumen.

\section{MEA (Monitor, Evaluate and Assess) dalam Meningkatkan Kualitas Layanan}

Tabel 6 menunjukkan hasil dari pengujian hipotesis 3 yang memiliki hubungan antara MEA dengan kualitas layanan. Berdasarkan hasil pengujian dapat dijelaskan bahwa nilai original sampel memberikan informasi besar koefisien parameter sebesar 0,285 yang berarti terdapat pengaruh yang positif EDM di Universitas dalam meningkatkan kualitas layanan dengan nilai t-statistik sebesar 4.098 dan nilai PValue sebesar 0,000. Hal ini menunjukkan bahwa hipotesis 3 diterima dan berdasarkan hasil tersebut terdapat pengaruh antara MEA dalam meningkatkan kualitas layanan. Hal ini sesuai dengan studi literatur dari (Ghozali \& Latan, 2015) yang dapat diartikan bahwa terdapat pengaruh yang positif dan signifikan penerapan COBIT 5 dengan indikator MEA (Monitor, Evaluate and Assess) di Universitas Trilogi dalam meningkatkan kualitas layanan informasi. 
Dari penjabaran yang dijelaskan pada Tabel 6, dapat disimpulkan bahwa MEA (Monitor, Evaluate and Assess) dapat dijalankan dengan baik pada sistem informasi akademik kampus karena adanya upaya yang dilakukan oleh universitas dalam melakukan pemantauan berjalannya sistem agar sesuai dengan tujuan operasi sistem itu sendiri atau sesuai dengan peraturan dan tata kelola universitas. Hal ini mendukung penelitian Vitrin dkk. (2019) bahwa dengan melakukan pemantauan dan evaluasi agar sesuai dengan data yang diberikan, diperlukan sebuah pengendalian yang baik pada internal perusahaan dan ketaatan terhadap peraturan yang berlaku. Penelitian Hakim dkk. (2014) bahwa dengan melakukan optimalisasi pada sistem pelaporan sesuai dengan perencanaan dan berpedoman pada kebijakan dapat memberikan hasil yang sesuai dengan yang diberikan kepada pemangku kepentingan. Penelitian Utomo \& Novita (2011) bahwa dengan adanya batasan proses yang harus beroperasi dengan laporan Monitoring dapat memberikan pelaporan yang sistematis dan tepat waktu kepada konsumen. Responden menunjukkan jika dalam proses penerapan MEA yang diterapkan pada sistem informasi akademik berpengaruh positif baik dari sisi tangible, reliability, responsiveness, assurane hingga empathy terhadap kepuasan yang diberikan kepada mahasiswa dengan memberikan data yang sesuai kepada mahasiswa, melakukan evaluasi setiap ada keluhan pada sistem, dan menerima masukan untuk pengembangan sistem informasi akademik kampus.

\section{KESIMPULAN}

Penerapan COBIT 5 dengan variabel EDM, dan MEA memiliki pengaruh positif terhadap peningkatan kualitas layanan pada Universitas Trilogi yang diberikan melalui sistem informasi akademik, sedangkan variabel DSS tidak berpengaruh terhadap peningkatan kualitas layanan pada Universitas Trilogi yang diberikan melalui sistem informasi akademik. Dan hasil kesimpulannya adalah Universitas Trilogi sudah melakukan optimalisasi risiko pada sistem, memberikan kelengkapan menu untuk pengurusan perkuliahan pada sistem, dan memberikan informasi yang transparan, serta melakukan pemantauan, dan mengevaluasi kesesuaian informasi pada sistem informasi akademik kampus. Namun, Universitas Trilogi belum dapat menjalankan pengelolaan keberlanjutan layanan pada sistem karena sistem belum ada fitur bagi mahasiswa untuk melakukan laporan atas insiden yang dialami mahasiswa.

Oleh karena itu, solusi untuk dapat meningkatkan kualitas layanan pada sistem informasi akademik kampus adalah dengan memahami dan menerapkan secara baik kerangka kerja COBIT 5 dengan semua variabel yang ada di dalamnya untuk mengurangi semua risiko yang dapat menyebabkan universitas tidak dapat mengelola insiden sehingga diperlukan peningkatan bertahap dalam mengembangkan sistem berkelanjutan yang dapat menjangkau mahasiswa dari semua aspek baik dari pengadaan menu, penerimaan insiden layanan dan transparansi laporan agar dapat meningkatkan kualitas layanan dengan memberikan mahasiswa alat penunjang baik dari segi fisik sampai penunjang lainnya, agar kualitas layanan yang diberikan sesuai dengan harapan mahasiswa baik dari sisi sikap atau tanggapan yang diberikan untuk menanggapi setiap keluhan yang ada, sebuah jaminan atau kepastian yang diperoleh dan sikap dalam memberikan perhatian lebih secara tulus kepada mahasiswa tanpa ada imbalan lebih yang diharapkan agar tercipta pelayanan yang efektif dan efisien yang tersampaikan kepada mahasiswa.

\section{DAFTAR PUSTAKA}

Anggraeni, E. Y., \& Rita, I. (2017). Pengantar Sistem Informasi. Yogyakarta: ANDI.

Fikri, S., Wiyani, W., \& Suwandaru, A. (2016). Pengaruh Kualitas Pelayanan Terhadap Kepuasan Dan Loyalitas Mahasiswa. Jurnal Bisnis dan Manajemen, 3(1), 120-134. https://doi.org/10.26905/jbm.v3i1.80.

Ghozali, I. (2015). Partial Least Square Konsep, Teknik, dan Aplikasi menggunakan program SmartPLS 3.0. Semarang: Badan Penerbit Universitas Diponegoro. 
Hakim, A., Saragih, H., \& Suharto, A. (2014). Evaluasi Tata Kelola Teknologi Informasi Dengan Framework Cobit 5 Di Kementerian Esdm (Studi Kasus pada Pusat Data dan Teknologi Informasi ESDM). Jurnal Sistem Informasi (Journal of Information Systems), 10(2), 108-117. https://doi.org/10.21609/jsi.v10i2.393

IT Governance Indonesia. (2019). Perbedaan Tata Kelola dan Manajemen Berdasarkan COBIT. https://itgid.org/perbedaan-tata-kelola-dan-manajemen-berdasarkan-cobit/

Kotler, P., \& Keller, K. L. (2016). Marketing Management. London: Pearson.

Lutfianto, A. (2014). Analisis Tata Kelola Teknologi Informasi Dengan Framework COBIT 5 Domain EDM01 Pada Politeknik Harapan Bersama Tegal. Universitas Dian Nuswantoro.

Maskur, Adolong, N., \& Mokodongan, R. (2017). Implementasi Tata Kelola Teknologi Informasi Menggunakan Framework Cobit 5 Di BPMPTSP Bone Bolango. Jurnal Masyarakat Telematika dan Informasi, 8(2), 109-126. https://doi.org/ 10.17933/mti.v8i2.106.

Maulidia, N., Rochimah, S., \& Affandi, A. (2013). Perkembangan Prosedur Untuk Optimalisasi Kualitas Sistem \& Layanan Jaringan TIK Dengan Cobit 4.1 dan ITIL. V3. Prosiding Seminar Nasional Management Teknologi XVII, 1-9.

Pardiansyah, A. S. (2015). Audit Tata Kelola Teknologi Informasi Program Studi Sistem Informasi Sekolah Tinggi Manajemen Informatika dan Komputer (STMIK) Lombok Menggunakan Framework Cobit. IJSE - Indonesian Journal on Software Engineering, 1(1), 17-25. https://doi.org/10.31294/ijse.v1i1.591

Sekaran, U., \& Bougie, R. (2013). Research Methods for Bussiness. New York: Wiley

Sevima. (2020, Juli 20). Sistem Informasi Akademik Terintegrasi dan Lengkap. Sevima. https://sevima.com/sistem-informasi-akademik/

Sitohang, H. T. (2015). Penerapan Tata Kelola Teknologi Informasi Dengan Menggunakan Cobit Framework 4.1 Studi Kasus Pada PT. Perkebunan Nusantara III Medan (PERSERO). Jurnal Mantik Penusa, 17(1), 1-7.

Sugiyono. (2011). Metode Penelitian Kualitatif, Kuantitatif dan R\&D. Bandung: Alfabeta.

Supardono, B. (2011). Tingkat Kematangan Tata Kelola Teknologi Informasi (IT Governance) pada Layanan dan Dukungan Teknologi Informasi (Kasus: Perguruan Tinggi Swasta di Kota Semarang). Proceeding Seminar Nasional Teknologi Informasi \& Komunikasi Terapan (Semantik), 1(1).

Suryono, R. R., Darwis, D., \& Gunawan, S. I. (2018). Audit Tata Kelola Teknologi Informasi Menggunakan Framework Cobit 5 (Studi Kasus: Balai Besar Perikanan Budidaya Laut Lampung). Jurnal Teknoinfo, 12(1), 16-22.

Utari, R. D., Budiono, ST., MT, A., \& Santosa, SSi., MTi, I. (2018). Perancangan Tata Kelola Teknologi Informasi Pada Layanan Marketplace Business To Business Menggunakan Kerangka Kerja Cobit 5 Domain Evaluate, Direct and Monitor (EDM) dan Monitor, Evaluate and Assess (MEA). Proceeding of Engineering, 3466-3473.

Utomo, A. P., \& Novita, M. (2011). Analisis Tata Kelola Teknologi Informasi (IT Governance) pada Bidang Akademik dengan COBIT Frame Work Studi Kasus Pada Universitas Stikubank Semarang. Jurnal Teknologi Informasi Dinamik, 16(2), 139-149.

Vitrin, C. I., Kraugusteeliana, \& Muliawati, A. (2019). Rancangan Indikator Audit Sistem Informasi Kepuasan Pelanggan Menggunakan Framework COBIT 5 Domain DSS, ME dan, EDM (Studi Kasus BPJS). Proceeding Seminar Nasional Informatika, Sistem Informasi dan Keamanan Siber (SEINASIKESI), 1-6.

Wahono, B. B. (2015). Peningkatan layanan sistem informasi kesehatan (studi kasus diinas kesehatan kabupaten jepara). Simetris: Jurnal Teknik Mesin, Elektro dan Ilmu Komputer, 6(1), 101-110. 
Wicaksono, M. A., Rahardja, Y., \& Chernovita, H. P. (2020). Analisis Tata Kelola Teknologi Informasi Menggunakan Framework Cobit 5 Domain EDM. JSIL: Jurnal Sistem Informasi, 7(1), 25-33. https://doi.org/10.30656/jsii.v7i1.2027.

Wijayanto, Y. B., W, B. S., \& Amborowati, A. (2018). Audit Tata Kelola Teknologi Informasi Rumah Sakit Menggunakan Framework COBIT 5 (Studi Kasus di RS Panti Rapih). TEKNOMATIKA: Jurnal Informatika dan Komputer, 10(2), 33-44.

Zamzami, F., Faiz, I. A., \& Mukhlis. (2015). Audit Internal Konsep dan Praktik. Yogyakarta: Universitas Gadjah Mada Press.

Zamzami, M., \& Novita. (2020). Apakah Gemba Kaizen Mampu Meningkatkan Kinerja Nonkeuangan Pendidikan Tinggi? Jurnal Akuntansi Multiparadigma, 12(1), 207-220. https://doi.org/10.21776/ub.jamal.2021.12.1.12. 